\title{
Transformation and Upgrading Strategy of Professional Towns in Guangdong during the "Internet+" Period
}

\author{
Jinping Wang \\ College of Business Administration, South China University of Technology, Guangzhou, China \\ Email: wangjpjob@163.com
}

How to cite this paper: Wang, J.P. (2018) Transformation and Upgrading Strategy of Professional Towns in Guangdong during the "Internet+" Period. American Journal of Industrial and Business Management, 8, 1587-1602.

https://doi.org/10.4236/ajibm.2018.86106

Received: May 2, 2018

Accepted: June 22, 2018

Published: June 25, 2018

Copyright ( 2018 by author and Scientific Research Publishing Inc. This work is licensed under the Creative Commons Attribution International License (CC BY 4.0).

http://creativecommons.org/licenses/by/4.0/

\section{(c) (i) Open Access}

\begin{abstract}
The upgrading strategy of professional towns is an important guarantee for the transformation of the economic development mode. At present, the economic development of Guangdong Province of China is facing a new situation of changing modes, adjusting structures, and changing forces [1]. How to speed up the transformation and upgrading of professional towns and promote economic development in the township, and thus promote the rapid economic development of Guangdong Province of China, is a serious challenge. The study finds that although the collaborative innovation development of professional towns in Guangdong Province of China is effective, there are still many problems and deficiencies: 1) low level of collaborative innovation; 2) narrow scope of collaborative innovation; 3) single structure of collaborative innovation; 4) a low dimension of collaborative innovation. This research is based on the new era of the "Internet+" development and takes the lead in collaborative innovation research based on the perspective of the development of the town-region economy, and proposes innovative research results for the collaborative innovation of professional towns and professionalism for Guangdong Province of China [2]. Based on this, this research is mainly based on the summary of the current situation and problems in the development of professional townships, and builds the "Six Major Systems Collaborative Practice" from the six dimensions of management factors, enterprises, industries, platforms, and "government, industry, research and application". The new models what the town has is about innovation and development.
\end{abstract}

\section{Keywords}

"Internet+", Professional-Town Upgrade, Collaborative Innovation 


\section{Background and Significance}

\subsection{Research Background}

Professional towns are based on the town (district) as the basic geographical unit, the relative concentration of the leading industries, and the economic scale is large, and the professional supporting cooperation has a relatively high level of a cluster of economic development carriers and models. By the end of 2016, there were 399 provincial-level certified professional towns across the province, covering mechanical, hardware, textile and clothing, home appliances, furniture, auto parts, building materials, ceramics, agriculture and other traditional industries as well as electronic information, creative design, e-commerce, and ecology. Emerging industries such as tourism have achieved a GDP of 2.77 trillion yuan, accounting for $38 \%$ of the province's GDP. It is estimated that by 2020 , the number of provincial-level professional towns in Guangdong will reach 500, and the total GDP of professional towns will strive to exceed RMB 4 trillion, and the coverage of professional towns' collaborative innovation platforms will reach over $90 \%$.

The era background of the "Internet+" development has brought major opportunities for the collaborative innovation and development of professional towns [3]. In 2015, Premier Li Keqiang even introduced the concept of "Internet Plus" in the "Government Work Report". He also pointed out that the "Internet+" action plan should be formulated to promote the integration of mobile internet, cloud computing, big data, and internet of things with modern manufacturing, promote the healthy development of e-commerce, industrial internet, and internet finance, and guide Internet companies to expand the international market.

"Internet+" represents a new economic form. It is based on the Internet platform, uses information and communication technologies to cross-industry integration across industries, promotes industrial transformation and upgrading, and continues to create new products, new businesses and new models [4], building a new ecology that links everything. With the development of Internet information technology and changes in consumer demand, the industry boundary has become increasingly blurred. Collaborative innovation strategy based on this is no longer suitable for the current development needs. Therefore, the connotation and extension of collaborative innovation also urgently needs to expand new scope [5]. Based on this, using the opportunities provided by "Internet Plus", professional towns will explore new modes for realizing collaborative innovation and development through realizing multi-subject and multi-system interconnection and interoperability, which can effectively promote the transformation and upgrading of professional town-specific industries and improve Industrial cluster competitiveness [6].

\subsection{Research Significance}

\subsubsection{Practical Significance}

Research has expanded the concept of collaborative innovation, detailed six le- 
vels and four dimensions of collaborative innovation in professional towns, and provided direction for collaborative development of professional towns.

\subsubsection{Theoretical Significance}

"Internet+" develops a new situation, expands the concept of narrowly defined corporate collaborative innovation in the past, takes the lead in researching collaborative innovation based on the development perspective of a town-region economy, and proposes innovative research results [7]. Domestic scholars conducted relevant research on professional towns and achieved certain results. At the same time, foreign countries have also profoundly elaborated on industrial clusters and cluster companies. With regard to the meaning of professional towns, from what perspective and in what form it is used to carry out transformation and upgrading, there are often many opinions and opinions, and benevolent people are interested. The formation mechanism is also rarely seen by scholars. Therefore, from the perspective of collaborative innovation, the issue of the transformation and upgrading of professional towns in Guangdong is discussed, and the meaning and forming mechanism of collaborative innovation are discussed. Then a practical and feasible strategy for the development strategy of professional towns is proposed, which can enrich the research results in related fields and has important theoretical significance [8].

\section{Research Status at Home and Abroad}

\subsection{Domestic Research Status}

\subsubsection{Research Status of Professional Towns}

In recent years, domestic research on the status quo and future development of professional towns has also gradually increased. In terms of the connotation and importance of professional towns, Bai Jingkun and Zhang Shuangxi believe that specialized towns are the regions with competitive advantages of domestic and foreign industries under the economic development of the town and the coordinated development of leading industries and supporting industries within the township. The rural economy has entered an important way of organizing the international commodity chain of manufacturing. Shi Yishao believes that the rise of professional towns has significantly enhanced county and city economic strength and competitiveness, formed an effective combination of geographical division of labor and industrial division of labor, and was conducive to the integration of production, supply and marketing [9] [10] [11] [12].

Zhu Guilong and Zhong Nature pointed out that professional towns in Guangdong have become important innovation and growth poles for the economic development of Guangdong Province through the accumulation of characteristic industries and the construction of industrial ecosystems.

In view of the current development status and characteristics of professional towns, Shi Yishao pointed out that professional towns mainly have the disadvantages of low economical industrial level and low technical content [13], but the dominant industries are prominent and have a high market share. The pri- 
vate economy is the main body of its economy. The commercial trade circulation professional market is coexisted with the cluster of production and processing enterprises. It has the characteristics of network organization and has historical and cultural inheritance. From the perspective of specialized town management activities, Wang Huanqi divided professional towns into two categories: one is a specialized town with resources outside and the market is outside, and the other is a specialized town with resources outside the market. Zhu Guilong and Zhong Nature summarized the development history of the four professional towns through research: budding period, formation period, growth period and innovation period. At the same time, it was pointed out that professional towns have characteristic industry clusters and gradually form a comparative advantage within the township administrative area. The perfect industrial ecosystem has two characteristics [14].

\subsubsection{Research on Collaborative Innovation Strategy}

The concept of collaboration was first proposed by Ansoff in 1965. It mainly refers to the symbiotic relationship between the two companies on the basis of resource sharing. Chen Guang defines collaborative innovation as a process in which the relevant elements of an enterprise's innovation are organically coordinated to produce overall synergies that cannot be achieved by separate elements through complex nonlinear interactions [15]. Some scholars will collaborate on innovation at two levels: First, horizontal collaborative innovation: refers to the synergy among subdivided industrial entities in the same major industry; second, vertical collaborative innovation refers to the synergy among the industrial entities in different links of the same functional chain.

Xiong Li et al. classified collaborative innovation as an internal collaborative innovation model related to the core elements (technical and market) and several supporting elements (strategic, cultural, institutional, organizational, management, etc.) related to internal corporate innovation. Universities, research institutes, government, etc., are the main external collaborative innovation models, i.e., the horizontal and vertical collaborative innovation models of various entities [16].

Wang Chuanlei also classified collaborative innovation into internal systems and external systems. It is believed that the internal system mainly refers to the specific innovation content of collaborative innovation. The internal system of the organization consists of technology, strategy, organization, market, manpower, culture, system, resources, and information, among which the basic key elements of consensus are technology and strategy [17]. Organization and system. The realization of collaborative innovation outside the organization mainly depends on the interaction between the industrial organization and other relevant entities. It mainly focuses on horizontal collaborative innovation and vertical collaborative innovation. At present, there is no universally applicable model for collaborative innovation systems. Research at home and abroad mainly draws on the analysis framework of regional innovation system, focuses 
on resource integration, and bundles a technological innovation chain around the dimensions of scientific research, market, system, and production [18].

\subsection{The Status of Foreign Research}

There are few studies on professional townships in foreign countries, but professional towns are an industrial cluster in their essence. Most studies on the transformation and upgrading of professional towns are also based on the theory of industrial clusters. In the late 19th century, Marshall put forward the concept of "industrial zone" [19]. Since the end of the 20th century, Western scholars have put forward the concept of "clusters" (see Michael Porter, "Clusters and Economics of New Competition"), arguing that "clusters are related to each other in a specific area and are A collection of companies and institutions focused on location." The competition between regions is actually the competition of industrial clusters [20]. Hotlin (1929) believes that the essence of location selection and spatial competition in industrial clusters is oligopoly.

In summary, scholars are studying the development of collaborative innovation from the perspective of regional and industrial clusters. This study took the lead in the collaborative innovation research from the perspective of the township, that is, the collaborative innovation of professional towns was driven by common interests. Multiparty entities such as universities, research institutes, governments, and intermediary agencies are supported by an external support environment to exchange knowledge, technology, organization, strategy, and other essential resource resources to form their own collaborative innovation organization model and achieve healthy operation and achieve synergy [21], to complete innovation breakthroughs, and achieve a win-win situation in a collaborative multiparty, and ultimately promote the transformation and upgrading of the economy in Guangdong Province, and then realize the "cage for bird" strategic policy.

\section{Literature Review}

1) Construction of a Strategic Model for the Transformation and Upgrading of Professional Towns in Guangdong in the New Stage of "Internet+"

The implementation of innovation-driven development strategies, and strive to initially build innovative Guangdong in 2017, is the overall starting point for the strategic restructuring and transformation of the province's economic structure [22]. The professional township is a private economy and small and medium-sized enterprise clustering area in Guangdong Province, and is an important support for the economic development of Guangdong Province. At present, the economic development of Guangdong Province is facing a new situation of changing the mode, adjusting the structure and changing the momentum. Town innovation and development rely on scientific and technological innovation to create new advantages in international competition [23]. Therefore, it is a stra- 
tegic requirement for the economic development of Guangdong Province to do a good job in the construction of a collaborative system for professional towns.

The rise of specialized towns has significantly enhanced the economic strength and competitiveness of counties and cities, formed an effective combination of geographical division of labor and industrial division of labor, and was conducive to the integration of production, supply and marketing. However, there are still many problems in the development of professional towns, and collaborative innovation is still at a lower level [24]. At the same time, with the deepening of the "Internet Plus" technology and Industry 4.0, the laggards will be eliminated, and the strategic trend of transformation, upgrading, and win-win cooperation in professional towns is imperative. Therefore, the construction of the "Internet+" collaborative mode of professional towns in Guangdong Province, the integration of characteristic industrial resources, and the full inflow of all innovative sources have become the key to improving the competitiveness of professional towns and even Guangdong Province [25]. Most of the previous scholars are studying the development of collaborative innovation from the perspective of regional and industrial clusters. This study took the lead in collaborating on innovation from the perspective of the township. That is, the collaborative innovation of professional towns is driven by common interests, enterprises, and universities. Multi-stakeholders such as research institutes, governments, and intermediary agencies are supported by an external support environment to exchange knowledge, technology, organization, strategy, and other essential resources to form their own collaborative innovation organization model and achieve a healthy operation to achieve a synergy effect. Breakthroughs in innovation and the realization of a win-win situation with multiple parties. Based on the development status of professional towns in Guangdong Province, this study proposes a collaborative innovation integration model for professional towns in Guangdong Province during the "Internet+" period, namely, a new strategy model for the development of professional towns in the "provincial towns with synergy and cooperation" [26]. "The six major systems collaborate simultaneously" professional town innovation and development new strategic model divides the synergy into internal and external synergy based on the scope of the town area. Internal synergy refers to management elements, enterprises, industries, industrial chains, platforms, and "political products". "Study and research" uses the "six-systems collaboration" to refer specifically to the full influx of talents, funds, and technology within a professional town, the promotion of collaboration among companies, industry integration and collaboration, the synergy of industry chain collaboration and integration on platforms, and "political research Use "multi-party collaboration." External collaboration means that the six major systems of different professional towns and different regions coordinate with each other, and at the same time, various innovative entities within the company achieve collaborative innovation across the township. Collaborative innovation systems are mutually influential, mutually 
restrictive, and mutually reinforcing, and their scopes also overlap. Management elements, enterprises, industries, industries, platforms, and "political and industrial research and use" are neither completely included nor independently. They are a complete system and they are all part of a large collaborative system, organically combined to create innovative effects.

\section{2) Management Elements Collaborative Innovation}

The synergy of management elements mainly includes the coordination of talents, technology, and funds [27]. It is an essential element that exists in the cooperation between internal and external parties. Talents refer to the active measures taken by various professional towns in attracting and attracting talents. At the same time, they focus on the training of local talents. They also jointly cooperate with universities and colleges and research institutes to carry out project cooperation and improve their practical ability. They are truly economical in the township. Development contributes. The technical aspect refers to the establishment of technical innovation platforms in the town, integration of technical resources and information of universities and R\&D teams of enterprises, construction of communication bridges, and promotion of scientific and technological cooperation. Funding refers to the provision of public funds for the development of regional industries by the township government. The company provides financial support for technological innovation, talent training and new enterprise creation. Three kinds of management elements are mutual support and mutual influence [28]. Only when the source of talents, technology, and capital is fully flowed and coordinated, can the innovation vitality in a professional town be truly expressed.

\section{3) Corporate Collaborative Innovation}

As the complexity of technology, the uncertainty of technological innovation, and the convergence of innovative technologies have intensified, the ability of individual companies to innovate has been increasingly challenged, and cooperation and innovation under the conditions of networks have begun to become more generalized. Especially in the era of "open innovation", more and more companies have begun to form collaborative networks through contractual relationships, cooperation networks, and social relations with other companies, universities, research institutions, governments, and intermediary agencies. However, collaborative innovation between enterprises is a complex dynamic behavior. Factors such as industrial environment, enterprise scale, overall industry technology level, entrepreneurship, and inertia can profoundly affect collaborative innovation among enterprises. The collaborative innovation defined by enterprises in this research refers to the synergy of all enterprises in a professional town, including the cooperation of the same industry chain and cross-industry chain, the same professional towns and multi-professional towns, or the growth of an enterprise as an integrated resource [29]. The entrance of the company involved all the fields involved, including the coordination of resources and business collaboration. 


\section{4) Industrial chain collaborative innovation}

Industrial chain is a concept in industrial economics. It is a chain-type association relationship that is based on a certain technical and economic relationship between various industrial sectors and is based on specific logical relationships and spatial-temporal layout relationships. It includes the concept of four dimensions: value chain, enterprise chain, supply chain and space chain. These four dimensions formed the "docking mechanism" of the industrial chain in the process of mutual docking. This is also the intrinsic mode of industrial chain formation. As an objective law, he regulates the formation and development of the industrial chain like an "invisible hand". The collaborative innovation of the industry chain defined in this study refers to the optimization and upgrading of the value chain, enterprise chain, supply and demand chain and space chain, so that the middle and lower reaches of the industrial chain can achieve a multi-win situation of improving efficiency and reducing costs. The core purpose of synergy as an internal factor industrial chain is to open up all links between the upstream and downstream industries of a specialty industry within the town, and to enhance the competitiveness of the enterprise and industry [30].

\section{5) Industry collaborative innovation}

The industry generally refers to the types of economic activities that are classified according to the production of similar products or have the same technological process or provide similar labor services, such as the catering industry, clothing industry, machinery industry, financial industry, and mobile internet industry. The industry collaborative innovation defined in this study mainly refers to the collaboration among the enterprises within the specialized industries within the town, the collaboration between the specialized industries within the town and the related industries, and the cooperation between the government and the universities supported by the industry organizations as the intermediary. Organizations can also collaborate on innovation across the township [31].

\section{6) Platform collaborative innovation}

The platform was originally an engineering concept. The successful application of its method in engineering practice has led the platform theory to a wide range of management theorists and has resulted in a number of special studies on platform methods such as product platforms, information platforms, and management platforms. There are two main aspects of platform collaborative innovation defined in this study. The first is to build a public service platform for special industries, integrate internal resources, and coordinate internal functions to stimulate the continued innovation of the platform. Second, under the support of the government, joint universities and research Institutes and related industries, integrating characteristic industrial resources, stimulating the continued innovation and vitality of the platform [32]. At the same time, various platforms within and outside the town will cooperate with each other to create a synergy effect.

7) “Administration, production, learning, research, use" collaborative 


\section{innovation}

Collaborative innovation of "Administration, production, learning, research, use" refers to the coordination and integration among innovative entities such as governments, enterprises (industries), institutions of higher learning, scientific research institutions, and market users in the "Internet+" environment, realizing technological innovation and realizing the economy [33]. The transformation and upgrading of the structure will achieve the purpose of promoting economic development. Essentially, the "Administration, production, learning, research, use" synergy is the organic combination of the administrative field, the production field, and the knowledge field, the realization of the combination of knowledge, and the unity of people. Specifically, the "Administration, production, learning, research, use" collaborative innovation model is under the leadership of the government to realize the cross-organizational integration of the economic elements represented by economic organizations (companies) and the knowledge elements represented by science and technology organizations (colleges and research institutes). Combining technology with production, and creating important collaborative innovations for users' innovation in terminals (consumers). In addition, innovative entities such as governments, companies, institutions of higher learning, and market users can also collaborate across towns."Cooperation between government, industry, and research" is also a kind of strategic collaboration, organizational coordination, and knowledge synergy. It can achieve innovative research and market application in government, industry, universities, and research institutes [34].

\section{Countermeasures and Suggestions for the Transformation and Upgrading of Specialized Towns in Guangdong Province in the "Internet Plus" Period}

In view of the above-mentioned problems in the development of collaborative innovation in professional towns, this study proposes that the transformation and upgrading strategy for collaborative innovation in specialized towns should be carried out. First, the "promotion and innovation of professional towns should be built on the basis of the innovation and development model of professional towns with six major systems collaborating simultaneously". Figure 1 is what system of four-degree up scaling to co-ordinate the construction and development of the six major systems.

\subsection{Four-Dimensional Space}

\subsubsection{One-Dimensional Space}

Traditional collaborative innovation. The production of industrial clusters is purely artificial and purely mechanical, with almost no use of information equipment and information technology. There is no internal LAN and external Internet at all. There is a lack of effective integration and excavation of information [35]. Based on research and development of products, the cooperation of 


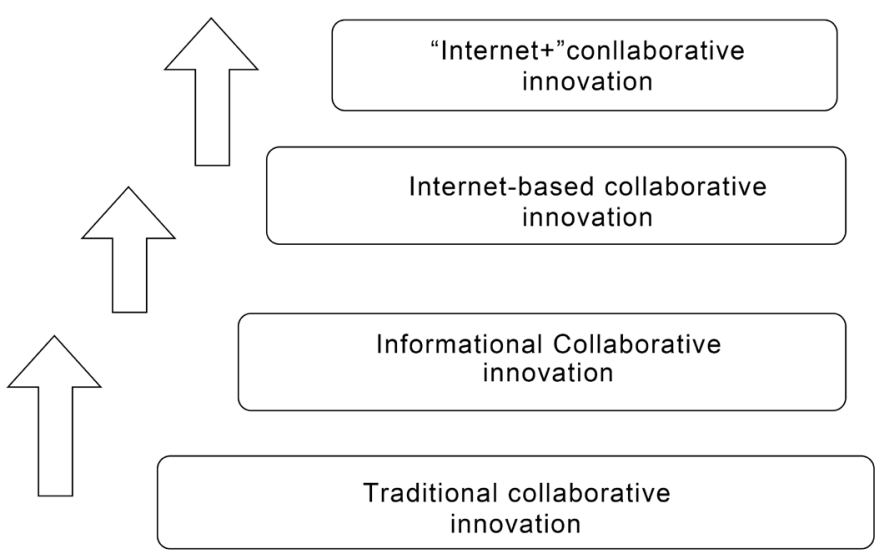

Figure 1. Four degrees of dimensionality upgrading system of professional towns' collborative innovation.

production, teaching and research is carried out, and it only serves product production.

\subsubsection{Two-Dimensional Space}

Informational collaborative innovation. Based on the integration of information and industrialization for collaborative innovation, the introduction of Internet engineering, and the exploration of databases and databases, the core is the reconstruction of production and supply chain and the management of market information. The purpose is to achieve economies of scale, and improve efficiency.

\subsubsection{Three-Dimensional Space}

Internet-based collaborative innovation. The use of "cloud, big, material, and shift" technology to carry out collaborative innovation, based on flexible production to provide customers with customized services, established internal and external networks, to create a flexible, customized production, research and development, service platform, and began to serve customers' personalized needs.

\subsubsection{Four-Dimensional Space}

"Internet+" collaborative innovation. "Internet+" is "cross-border" + "connection", based on the collaborative innovation of "entry economy", to achieve cross-enterprise, cross-industry, cross-platform, cross-domain, cross-regional integration, and its purpose is to meet the diverse needs of customers.

The collaborative innovation of professional towns in one-dimensional and two-dimensional spaces is based on their own scale and efficiency, and for production services; while the three-dimensional and four-dimensional dimensions are based on the satisfaction of individualized and diversified needs at the human level. It truly suits the Internet economy as an essential feature of a people-oriented economy and also embodies the service economy as a core value of humanistic care. Professional towns' collaborative innovation transformation and upgrading strategy is mainly divided into transformation from traditional collaborative innovation to information-based collaborative innovation, trans- 
formation from information-based collaborative innovation to internet-based collaborative innovation, and transition from internet-based collaborative innovation to the Internet. Collaborative innovation and transformation of the town are important. In order to keep up with the trend of the Internet economy, traditional collaborative innovation must first realize basic informationization, realize information standardization and standardized management, and use information-based low-cost, high-efficiency service scale production. Based on informatization, based on customer orientation, making full use of big data, cloud computing, and intelligent manufacturing technologies, one-to-one customized services for customers, and the introduction of a personalized and customized industrial 4.0 intelligent manufacturing model, realizing a large scale Customized model innovations. Based on the "Internet+" "cross-border integration, connecting all" characteristics, we must guide traditional collaborative innovation to break through the boundaries of existing industries and enterprises, and realize cross-border integration of resources through platformization and open collaboration [36].

In short, according to the "new normal" economic development strategy proposed by General Secretary Xi Jinping, professional towns should vigorously develop a service-led Internet economy at the current stage, seek industrial transformation and upgrading, take customer value as a guide, and take industrial integration as the basis. Informatization as a driving force, through the industrial segmentation and inter-industry differentiation, integration, cross-border, infiltration, promote the widespread application and diffusion of intellectual elements such as knowledge, information, creativity, science and technology in production economic activities, and then seize regional and global value.

\section{2. "Six Major Systems Collaborate Simultaneously" Counter Measures and Suggestions under the New Model}

In the face of new industry development trends brought about by the revolution in information technology, industrial upgrading, and consumer demand, professional innovation in professional towns in Guangdong Province needs innovation in the form of business organizations and operating models that meet customer needs [37]. The "dimensional system" explores how to promote the transformation of collaborative innovation in professional towns, and comprehensively strengthens the "six major systems" in terms of collaborative innovation.

\subsubsection{Countermeasures and Suggestions for Collaborative Innovation of Management Elements}

1) In terms of personnel: The town government must vigorously carry out the strengthening of IT complex talents;

2) Technical aspects: The first is to establish and improve the trust mechanism, The second is to standardize information sharing and protect intellectual property rights. Regulate information sharing mechanisms and issue corres- 
ponding measures and regulations for the protection of intellectual property rights.

\subsubsection{Countermeasures and Suggestions for Collaborative Innovation in Enterprises}

Enterprises must cultivate an innovative culture, be bold in transformation and seek collaborative innovation, enterprises must actively implement cross-border integration, provide one-stop program services, and the government should speed up infrastructure construction. The government needs to give full play to the guidance and amplification of fiscal policies and financial funds.

\subsubsection{Countermeasures and Suggestions for Collaborative Innovation of Industrial Chain}

This study proposes a brand-new development model based on the "Internet+" theory of the integrated production companies to solve the problem of incomplete and uncoordinated industrial chains in professional towns in Guangdong Province, and promote e-commerce transactions, credit security, logistics and distribution, and financing services, talents, technology R\&D and other services gather together to develop.

\subsubsection{Industry Collaborative Innovation Strategies and Suggestions}

In order to promote the industry's collaborative innovation to the "Internet + " dimension, we propose to build a collaborative innovation model that is Figure 2 for the industry.

This model takes the companies in the industry as the basic elements, and the outermost layer is three supporting units: government, industry colleges and research institutes, and industry organizations. The interaction and collaboration of the three are the supporting foundation for collaborative innovation in the industry. Located in the middle and outer layers is the enterprise cooperation unit, namely the enterprise technology innovation alliance, which is the

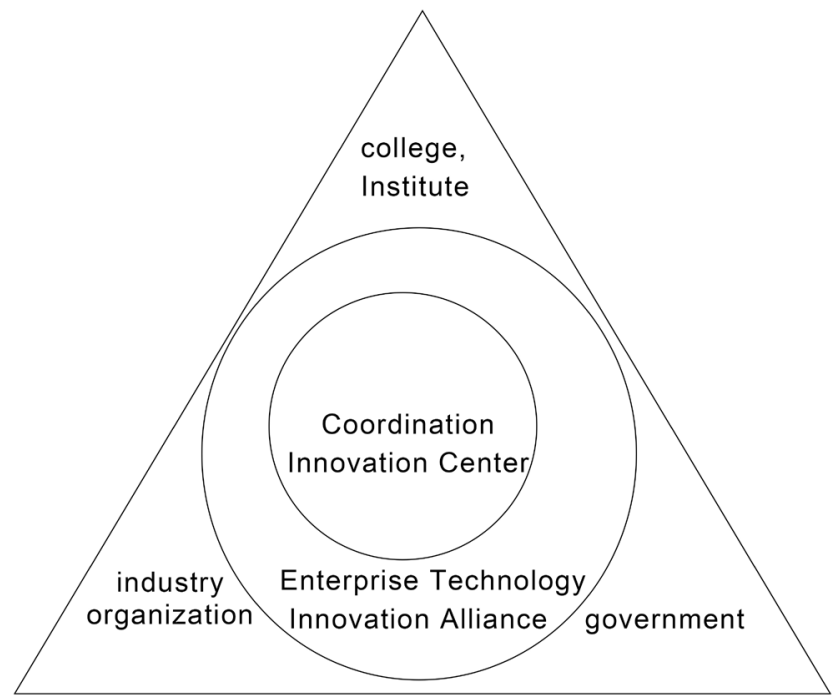

Figure 2. Industry-oriented collaborative innovation model. 


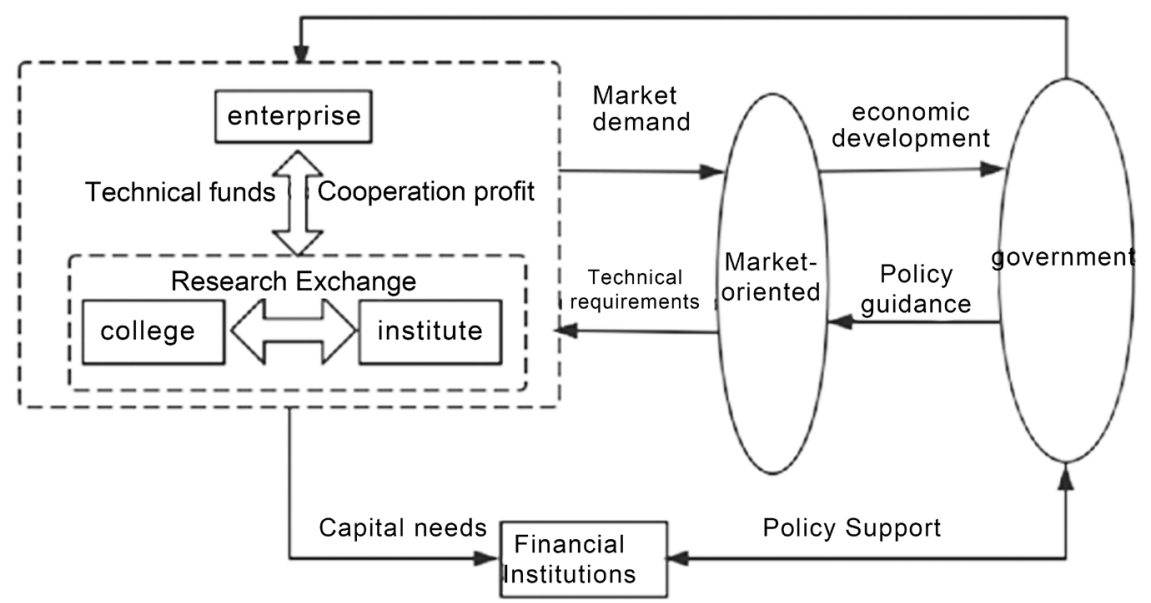

Figure 3. "College, Industry and Research" collaborative innovation model.

collaborative carrier of the enterprises within the industry and the output organization of the major achievements of collaborative innovation in the future. Located in the middle is the Collaborative Innovation Center, which is the ultimate integrated agency for collaborative innovation in the industry. Under the collaborative management of the center, companies in the industry form a technology alliance and carry out innovation activities under the support of industry universities and research institutes, industry organizations, and town governments. Industry-oriented collaborative innovation model [38].

\subsubsection{Platform Collaborative Innovation: Countermeasures and Suggestions}

The collaborative innovation of the platform defined in this study has two main aspects: first, build a public service platform for featured industries, integrate internal resources, and coordinate internal functions to stimulate continuous innovation; second, under the support of the government, joint universities and research Institutions, industry organizations, and other related institutions, integrating characteristic industrial resources, inspire the continued innovation and vitality of the platform. At the same time, different platforms inside and outside the town cooperate with each other to create synergy effects.

\subsubsection{Strategies and Suggestions for Collaborative Innovation of "Utilized Government, Production and Research"}

Strategies and Suggestions for Collaborative Innovation of "Utilized Government, Production and Research" In order to promote collaborative innovation of "government, industry, research, and use" and "Internet+" upgrade, we propose to create a market-driven collaborative innovation model as Figure 3-"political, industrial, academic research and use" to speed up the construction of a networked cooperation system for government, industry and research, and improve and establish information. Platform, strengthen policy support, and increase supervision. The following is the "College, Industry, and Research Collaborative Innovation Model". 


\section{References}

[1] Li, J.Y. (2016) Research on the Strategic Development Path of Enterprise Platform Based on Business Ecosystem-A Case Study of Gansu Province. Productivity Research, No. 2, 64-68, 80 .

[2] Wang, Y. and Yuan, Y.H. (2003) Research on Platform Strategy in the Development of New Products. China Soft Science, No. 4, 55-58, 41.

[3] Zhu, G.L. and Zhong, N. (2014) Driving from Factors to Innovation-Development of Professional Towns in Guangdong and Its Policy Orientation. Science in Science Studies, No. 1, 29-33.

[4] Bai, J.K. and Zhang, S.X. (2003) The Connotation of Professional Towns and the Analysis of China's Professional Town Types. Problems of Agricultural Economy, 12, 17-20, 79.

[5] Chen, X.W. and Huang, H.Y. (2016) Thinking on the Construction of Collaborative Innovation System in Professional Towns. Special Economic Zone, No. 4, 46-48.

[6] Qu, H.J. and Tuo, Z. (2013) Summary and Outlook of Collaborative Innovation Model Research. Industrial Technology \& Economy, No. 7, 132-142.

[7] Hu, T.T. and Wen, D.G. (2013) A Comparative Study of Innovation-Driven Development in Developed Countries. Scientific Management Research, No. 2.

[8] Yin, D.Z. (2013) Research Based on National Innovation-Driven Development. Scientific Management Research, No. 3.

[9] Wang, L.J. (2014) Research on Industrial Cluster Upgrading Based on Innovation. Central Party School of CPC.

[10] Wang, H.H., Xie, F.J. and Zhou, J.N. (2014) “4D” Collaborative Framework for Innovation-Driven Development Strategy in China from the Perspective of Innovative Ecosystem. Science \& Technology Progress and Policy, No. 17.

[11] Wei, J., Li, T.-Y. and Zhao, Y.-Y. (2015) The Overall Pattern, Realistic Predicament and Policy Trend of Innovation-Driven Development. China Soft Science, No. 5.

[12] Xie, X.M. and Liu, S.Y. (2013) A Review of Collaborative Innovation Evolution from the Perspective of Metropolitan Mesocosm. Economic Geography, No. 2, 68-75.

[13] Xie, H.F., Pan, Z.X. and Liu, Z.J. (2012) Thoughts on the Transformation and Upgrading of Professional Towns in Guangdong Province under the Trend of Production, Teaching and Research. Science and Technology Management Research, No. 9, 60-63.

[14] Ye, S.H. (2007) New Theory of Scale Economy. Contemporary Finance and Economics, No. 2, 10-15.

[15] Xie, X.M., et al. (2013) A Review of Collaborative Innovation Evolution from the Perspective of Metropolitan Mesosphere. Economic Geography.

[16] Chen, J. and Yang, Y. (2012) Driving Mechanism of Collaborative Innovation. Technology Economics, No. 8, 6-11, 25.

[17] Ye, W., Mei, L., Li, W., Wang, C. and Zhang, G. (2014) The Dynamic Mechanism and Incentive Policy of Collaborative Innovation-Based on the Perspective of Complex System Theory. Management World, No. 6, 79-91.

[18] Bai, J. and Yu, Y. (2015) Whether Government Support Promotes Collaborative Innovation in Industry, Universities, and Research. Statistical Research, No. 11, 43-50.

[19] He, Y. and Zhang, Y. (2015) Coupling Research on Collaborative Innovation Mod- 
els of Network Type and Industry, Academy, and Research. Science of Science and Management, No. 2, 62-69.

[20] Duan, J. (2014) Research on the Path of Cooperative Innovation Performance Enhancement of Industry, University, and Research Institute: A Theoretical Analysis Framework. Inner Mongolia Social Science, No. 2, 119-123.

[21] He, Y. (2012) The Theoretical Model of Collaborative Innovation of Industry, University, and Research Institutes. Studies in Science of Science, No. 2, 165-174.

[22] Xie, X., Wu, Y. and Zhao, Y. (2015) The Influence of Collaborative Innovation Influencing Factors and Collaborative Models on Innovation Performance: An Empirical Study Based on 316 SMEs in the Yangtze River Delta. Management Review, No. 8, 77-89.

[23] Xie, X. and Fang, L. (2015) Review and Outlook of Foreign Collaborative Innovation Research. Research and Development Management, No. 4, 16-24.

[24] Ba, J. and Jiang, F. (2015) Collaborative Innovation, Spatial Association and Regional Innovation Performance. Economic Research, No. 7, 174-187.

[25] Xie, X. and Liu, S. (2015) The Mechanism of Collaborative Innovation on the Effect of Collaboration and Innovation Performance. Management Science, No. 2, 27-39.

[26] Wan, Y., Zhang, N. and Lu, P. (2015) Research on Collaborative Innovation Risk and Its Formation Mechanism in Industrial Clusters. Management World, No. 2, 182-183.

[27] Chen, F. and Yan, J. (2015) Collaborative Innovation and Evolution of Emerging Industries: A Case Study of New Energy Vehicles. Science Research Management, No. 1, 26-33.

[28] Xiao, K., Xia, W. and Lu, X. (2014) Collaborative Innovation Leads the Cultivation of Technical Skills Talents. Education Exploration, No. 3, 11-14, 30.

[29] Liu, D. and Yan, C. (2013) Research on Collaborative Innovation Network Structure and Mechanism. Management World, No. 12, 1-4.

[30] Li, Z. and Liang, C. (2012) Analysis of Collaborative Innovation Operation Mechanism-Based on the Perspective of University Innovation Subjects. China Higher Education Research, No. 7, 81-84.

[31] Tension (2011) Strategic Significance and Policy Trend of Collaborative Innovation in Industry, University, and Research. Educational Research, No. 7, 18-21.

[32] Wang, W., Wu, Z., Yue, G., Bai, M., Di, J., Yue, H. and Zhang, Y. (2016) Research on the Theoretical Mechanism and Evaluation of Regional Collaborative Innovation. China Science and Technology Resources, No. 2, 50-57.

[33] Yun, Y. and Mi, Z. (2016) Research on the Path of Collaborative Innovation and Development in Jing-Jin-Ji Region. Modern Management Science, No. 5, 70-72.

[34] Xu, C. (2016) The Challenges and Countermeasures of Collaborative Innovation in the Beijing-Tianjin-Hebei Region. Journal of Beijing University of Economics and Management, No. 1, 9-15.

[35] Pan, X. and Li, J. (2014) Research on the "Rocket Model" and Its Mechanism of Regional Collaborative Innovation. Science \& Technology Progress and Policy, No. 15, 30-34.

[36] Gao, L., Jiang, F., Xiong, J., et al. (2014) The Formation Mechanism and Spatial Characteristics of Regional Collaborative Innovation. Industrial Technology \& Economy, No. 3, 25-32.

[37] Zhao, Y. and Zhao, S. (2015) Framework and Development Strategies of the Colla- 
borative Innovation System in the Beijing-Tianjin-Hebei Region. Science \& Technology, No. 15.

[38] Wang, L. (2014) Study on the Innovation of Industrial Clusters Based on Innovation. The CPC Central Party School. 